\title{
Narrando la Dictadura a la Infancia. Imágenes que trafican significados.*
}

\section{Narrating Dictatorship for Childhood. Images that Smuggle Meanings.}

\section{Resumen}

Los medios para la infancia presentan un campo privilegiado para explorar la reproducción de consensos e imaginarios sociales. En este artículo, nos aproximamos a cuatro obras recomendadas por la crítica especializada: los libro-álbumes La composición, Camino a casa y Un diamante en el fondo de la tierra y el cortometraje "Bear Story". En estos textos, lo verbal y lo visual se imbrican para hacer referencias a la violencia política en Latinoamérica. Asistida por teorías de semiótica visual - - y por la categoría de modalidad de la imagen introducida por Gunther Kress y Theo van Leeuwen - analizo cómo estos textos narran la dictadura reproduciendo así límites de una memoria colectiva sobre el pasado que elude la narración de la violencia. El análisis ideológico de estos textos es complementado con algunas reflexiones elaboradas sobre respuestas lectoras de profesores de educación básica así como de niños y niñas obtenidas en talleres de lectura realizados en Santiago de Chile.

Palabras claves

Palabra/imagen, animación, imaginarios sociales, memoria cultural.

\begin{abstract}
Children's literature and media presents a privileged field to explore the reproduction of social discourses and consensus. In this article, we approach four works recommended by critics and mediators: the picturebooks La composición, Camino a casa and Un diamante en el fondo de la tierra, and the short film "Bear Story". In these four texts, the interplay of the verbal and the visual makes references to political violence in Latin America. Assisted by visual theories - and by the category of image modality introduced by Gunther Kress and
\end{abstract}

* This article was funded by CONICYT PIA CIE160007. 
Theo van Leeuwen-, I analyze how these texts narrate dictatorship avoiding the remembrance of violence. The ideological analysis is complemented with reflections elaborated upon reader responses of primary education teachers as well as children obtained in reading workshops organized in Santiago de Chile.

Keywords

Word/image, animation, social imaginaries, cultural memory.

Hasta hace una década había muy pocos libros o películas para niñas y niños que hiciesen referencia a las dictaduras latinoamericanas, pero en los últimos años han aparecido un buen número de éstos, recibiendo creciente atención crítica (Troncoso Araya). Este avance parece responder por una parte a la distancia de los eventos. En Chile, por ejemplo, la publicación de textos relacionados se desató tras el aniversario número 40 del golpe de estado. También parecen responder a una ampliación de temas en la literatura infantil, que ya no considera que temáticas como el Holocausto y la guerra, por ejemplo, sean inapropiados sino necesarios de ser abordados en la literatura para los menores de edad (Evans 10; Nikolajeva Children's Literature Comes of Age: Toward a New Aesthetic 62; Kidd 120). La tematización de episodios traumáticos en las historias nacionales y la memoria histórica aparece marcada por la esperanza de que los menores de hoy serán quienes influenciaran el mundo del mañana, y de que conocer estos hechos hará que estos no se vuelvan a repetir (Snell and Hutchison 8). En este artículo, nos aproximamos a cuatro textos que hacen referencia a la violencia de estado, articulando significaciones verbales, visuales y materiales. Una mirada a ellos permite visibilizar imaginarios sociales y sus formas “contables", como llama Molly Andrews a aquellos relatos que prevalecen en la conformación de una memoria cultural compartida (Andrews). Andrews explica que la capacidad de narrar y aún más, de entender nuestras vidas, derivan de aquellas posibilidades esbozadas por la producción cultural donde ciertas vidas pueden ser contadas.

Los medios para la infancia - libros, películas, juguetes y música, entre otros- se producen en un campo vigilado. Hans Heino Ewers dice que los adultos serían los "guardianes de entrada" (Ewers 28) de la literatura infantil: los 
niños y niñas no sólo no escriben los libros que leen, sino que tampoco los compran, ni los publican, y rara vez los seleccionan. Los textos recomendados por lo que Ewers llama el "círculo mediador" (25) — profesores, bibliotecarios, editores- estarían así moldeados por esos valores que los adultos esperamos reproducir en las próximas generaciones. La literatura infantil aparece como un espacio patrullado por adultos que se posicionan como expertos (en infancia, en promoción de la lectura, en lo que sus propios hijos necesitan o desean), conformando así un espacio privilegiado para estudiar la reproducción de imaginarios sociales y discursos hegemónicos.

En este artículo exploro tres libros-álbumes y un cortometraje que aparecen, de forma repetida, en listas de material recomendado elaboradas por instituciones de promoción a la lectura en España y Latinoamérica ${ }^{1}$. El predominante rol de lo visual en estos libros, me refirió a un cuarto texto de amplia circulación internacional, que hace referencia a la dictadura chilena: "Bear Story", cortometraje premiado en 2016 con el Óscar en su categoría.

Me acerco en este artículo a esas obras explorando cómo se narra la violencia política y los abusos de la dictadura a un lector/espectador que se supone niño o niña. Los regímenes dictatoriales latinoamericanos han sido tematizados recurrentemente en el cine y la literatura por creadores del cono sur

${ }^{1}$ En la última década hemos visto la emergencia y propagación de listas de recomendación elaboradas por distintas instituciones que se divulgan a través de internet. Para el proyecto "Narrativas de normalidad y diversidad en el libro visual en español", realizado con el investigador Xavier Mínguez-López consideramos libros recomendados por distintas instituciones latinoamericanas asociadas a IBBY (International Board on Books for Young People) tales como Banco del Libro en Venezuela, Fundalectura en Colombia, Ibby México, así como las listas elaboradas por otras instituciones como la Fundación Cuatrogatos, en Miami, dedicada a promover la literatura en español en EE.UU., Canal Lector de la Fundación Germán Sánchez Ruipérez (que trabaja en colaboración con Ibby México y las bibliotecas escolares CRA de Chile). Por último, consideramos la lista de honor White Ravens elaborada por la Internationale Jugendbibliothek en Múnich. De todos los libros recomendados en estas listas, nos centramos en los libros visuales - libro álbumes, libros sin palabras (wordless picturebooks) y libros ilustrados en los que la imagen visual fuese un importante recurso- publicados originalmente en castellano, que estuviese recomendado para lectores menores de 11 años (una categoría que aparece en casi todos estos listados aunque a veces sin recurrir a la edad sino a categorías de competencia lectora). Del universo de libros recomendados por estas instituciones entre 2009 y 2015 que alcanzaba poco menos de 1.000 libros analizamos una muestra de 100 libros que corresponden a aquellos que más se repetían en los listados. Entre éstos, tres hacían referencia a la violencia de estado y son el objeto de análisis en este artículo. 
(Anabalon 93) y comienzan ahora a convertirse en tema de referencia en literatura infantil.

Largo ha sido el debate sobre cómo definir qué obras son "infantiles". La académica norteamericana Barbara Wall pone la atención en a quién se dirige la voz narrativa. Wall explica que la mayor parte de los libros para niños y niñas tienen un mensaje que está doblemente codificado: hay elementos a ser interpretados por ellos y otros sólo por adultos que son quienes compran, seleccionan y muchas veces leen los libros a los menores (Wall 35). Esta teoría de la doble codificación ha sido adaptada también al estudio de las audiencias en el cine, donde se ve cómo, desde 1970, han proliferado las propuestas para un espectador indiferenciado, especialmente en el cine de animación (Brown 21).

Tanto los libros como el cortometraje aquí seleccionados pueden relacionarse con esta idea de una audiencia indiferenciada que caracteriza a gran parte del cine de animación hoy, así como a la edición de sofisticados librosálbum donde se habla de un público objetivo crossover (Beckett 1-4). ¿Son estos textos dirigidos a los niños y niñas o, bien, a adultos que articulan una memoria histórica para la infancia? ¿A ambos? ¿Cómo se dirigen, entonces, a unos y otros? ¿Qué aprendemos de esa forma diferenciada de apelar a sus lectores imaginados? ¿A qué imaginarios sociales sobre la infancia responden?

Analizo estas narrativas haciendo foco en el interjuego de lo verbal y lo visual ya que allí parece articularse esta doble codificación para el niño-a y el adulto. Este análisis es asistido por conceptos de narratología, particularmente, por la noción de capas de "focalización” según elabora Mieke Bal tras Gerard Genette (Bal 33), una importante herramienta para entender el punto de vista y la ideología en relación a qué acceso nos da la voz narrativa a los sentimientos y pensamientos de los personajes. El análisis de la focalización nos permite también entrar a esa construcción de la infancia inocente a la que hay que proteger con textos especialmente producido para ellos: textos en los que se esbozan un posible horizonte de pensamientos y sentimientos de los niños. El análisis de la focalización no apunta sólo al texto verbal el que, como dice Bal, siempre es 
enunciado por un "yo", sino que también permite pensar en un punto de vista para la representación visual. La complejidad de lo visual puede ser también abordada con algunos conceptos y miradas de la semiótica como el concepto de modalidad visual elaborado por Gunther Kress y Theo van Leeuwen. En Reading Images. The Grammar of Visual Design, Kress y van Leuween establecen una tipología para medir cómo una cierta imagen tiene pretensión de verdad: llaman a atender a cuestiones como la saturación del color, la variedad de colores, el uso de fondo, la luminosidad y la representación (abstracta o figurativa), entre otros (163). Simplificando, diríamos que mientras más se parece una imagen a la fotografía que tomaría una cámara automática, mayor pretensión de verdad, de representar una realidad, tiene ésta. Kress y van Leeuwen llaman a esta pretensión de verdad una "alta modalidad". W.J.T. Mitchell ya advertía sobre cómo la invención de la perspectiva en el Renacimiento sentó las bases para la tiranía de la imagen actual que nos presenta representaciones como verdades (Mitchell 524). El close reading de estos textos se complementa así con aportes de respuestas lectoras obtenidas en tres talleres organizados en el marco de esta investigación (dos con profesores de educación básica y uno con niños de 5 a 10 años $)^{2}$. Algunas de las interpretaciones de profesores, niños, y niñas ayudan aquí a problematizar las interpretaciones y formas de circulación de estos textos.

${ }^{2}$ Los talleres se desarrollaron en julio y octubre de 2016 con profesores, y en diciembre 2016 con un grupo de 10 niños. En el caso de los profesores se les dio un tiempo para revisar el material para después someterlo a una discusión grupal orientada por la pregunta de cuáles de los ejemplos utilizarían en clase, cómo y para qué. La discusión fue abierta y grabada sin que utilizase ningún cuestionario. En el caso de los niños, se les leyó un solo libro - Un diamante en el fondo de la tierra - y luego se les pidió que dibujaran un posible otro final para esa historia. Esos dibujos se compartieron en una sesión grupal. En los tres casos se buscó obtener respuestas lectoras con la menor intervención del grupo de mediadores. En los talleres con profesores se trabajó con la doctora Daniela Cobos, investigadora en didáctica del arte, y con niñas y niños se trabajó con el equipo de mediación de la Biblioteca de Santiago liderado por Francisca Santibañez. 


\section{Violencia contenida}

Los tres libros aquí analizados coinciden en una focalización desde el personaje menor de edad: es a través de la mirada de la niña o niño en la historia que tenemos acceso a ésta y al mundo que en ésta se representa. Esa focalización nos conecta, por una parte, con esa expectativa de inocencia que los adultos proyectamos a la infancia y, por otra, nos conecta con una potencial agencia del personaje. Distintos autores que han estudiado la historia de la infancia y literatura infantil insisten en la importancia de entender la inocencia infantil como un constructo (cf. Kincaid; Rose; Gubar). En los tres libros aquí analizados, la focalización en el personaje menor de edad acaba boquejando una agencia mucho mayor a la esperada que desborda esa concepción de lo infantil como inocente.

La agencia y toma de conciencia política es muy evidente en $L a$ composición (Ekaré, Caracas, 2000); el libro trata precisamente de la transformación en sujeto político de un niño que presencia como los militares se llevan detenido a un hombre. El texto verbal está narrado con focalización en Pedro, un niño de un barrio de clase media que disfruta jugando al fútbol, pero que va a tomar conciencia de lo que significa vivir en dictadura y actuará en consecuencia. Esta focalización en el niño permite, precisamente, distinguir a este texto como uno que cuenta la dictadura desde la perspectiva de los menores, lo que se destaca en distintas recomendaciones de este libro. El narrador tiene acceso a los pensamientos y sentimientos del personaje — "Pedro sentía que las hojas susurrantes eran un estadio techado que lo ovacionaba cuando recibía un pase preciso" (6). Pero más tarde este mismo narrador evita decirnos qué pasa por la mente de Pedro cuando ve a militares que se llevan detenido al padre de su amigo Daniel. "Entonces Pedro vio que al padre de Daniel se lo llevaban dos hombres, arrastrándolo, mientras un piquete de soldados lo apuntaba con metralletas. Cuando Daniel quiso acercársele, uno de los hombres lo contuvo poniéndole la mano en el pecho" (11). 


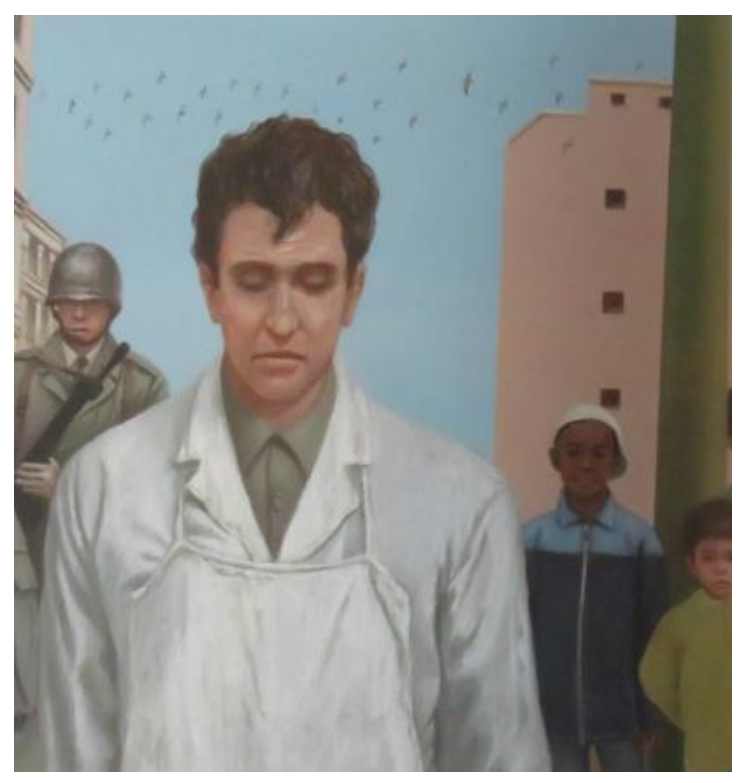

Figura 1. La composición

Al hombre se lo llevan a la fuerza y el narrador no nos dice si acaso Pedro tuvo miedo, ni cuánto podía intuir de lo que significaba esa irregular detención. ¿Por qué se lo llevan? ¿Qué ha hecho? Días más tarde llega un capitán militar a la escuela y les ordena a los niños hacer una composición sobre qué hacen sus padres en casa cuando llegan del trabajo. El narrador tampoco nos da acceso a lo que piensa Pedro cuando recibe este encargo. ¿Dirá la verdad? ¿dirá que escuchan esa señal de radio que llega muy débil? ¿que a veces llegaban amigos que "fuman como chimeneas y acercan la oreja al receptor"? Un lector que reconozca el contexto dictadura sabrá que lo que busca ese militar es obtener información sobre las familias disidentes, que es una trampa. La historia presupone a un lector que entienda esto, de otra forma los hechos posteriores pierden sentido. Que la narración de los pensamientos y sentimientos de Pedro no avance hasta allí, que no nos explique lo que él ahora entiende por dictadura y qué piensa él de esa composición encargada por el militar, permite el giro de sorpresa al final: sólo en la última página nos enteramos que el niño ha protegido a sus padres al reemplazar, en su composición, las escuchas de radio por un inocente juego de 
ajedrez. Pedro escribe que sus padres juegan ajedrez por las tardes. Son personas que ponen sus inteligencias en un juego considerado un deporte. Se derroca a un rey que no tiene relación alguna con un dictador. Un lector obnubilado por fantasías sobre la inocencia infantil no habría creído a Pedro capaz de "mentir" así. Pero ahí está. El niño nos sorprende. Cabe preguntarse cuánto sorprende a los niños y niñas que leen esta historia, niños a los que hay que explicarles una y otra vez por qué ese final y cuáles son esos militares de los que más valdría tomar distancia. Qué era la dictadura, a fin de cuentas.

Nos interesa pensar aquí cómo esa falta de avance de la focalización, cómo ese evitar compartir los pensamientos y sentimientos de Pedro cuando el aparataje de la dictadura entra en la historia, puede estar aquí reproduciendo lo que podríamos llamar "formas de callar". Hay cosas que no hay que poner por escrito, aunque sólo se trate de un relato para niños. El narrador no nos cuenta qué pasa por la mente de Pedro, ni Pedro dice nada sobre porqué inventó lo del ajedrez (34). Tras escuchar el relato que ha escrito Pedro, el padre dice que "por si las moscas" comprarán un tablero de ajedrez. A buen entendedor muy pocas palabras. El cuento acaba allí: el niño se ha convertido ya en un sujeto político que ha aprendido lo que puede decirse y lo qué no.

A diferencia de los otros textos aquí estudiados, La composición no fue creado como una narración visual, sino como un cuento, publicado por un diario venezolano en 1981. Skármeta, entonces exiliado en Berlín, se inspiró en los decretos que instaban a los profesores y directores de las escuelas a averiguar las tendencias políticas de alumnos y familias (González). Entonces la editorial Ekaré, fundada en Venezuela por una exiliada chilena y otra guatemalteca, tomó el proyecto de convertirlo en un libro, un trabajo que tomó casi dos décadas porque los primeros ilustradores a los que se les encargó la tarea no habrían podido dar con el tono del libro. Finalmente, se le encargó al español Alfonso Ruano, quién cuenta la historia con imágenes de alta modalidad, imágenes frecuentemente descritas como realistas, pero que evocan un ambiente de opresión. La elección de esta visualidad podría ser sintomática de un esfuerzo por 
suavizar el relato y, en particular, el texto verbal. Esto se hace patente en la imagen que acompaña el relato de la detención (Figura 1). Skármeta escribe que al hombre lo arrastran otros dos mientras un piquete de soldados apuntan con la metralleta, pero la ilustración muestra otra cosa. Llama la atención porque el libro se estructura bajo lo que Maria Nikolajeva y Carole Scott llamaron una relación simétrica entre lo visual y lo verbal: las ilustraciones se corresponden con lo que se encuentra escrito. Este formato es todavía el más común en libros álbum, pero hace un par de décadas era el formato: en general el texto escrito por un autor era entregado a un ilustrador, sin mayor reflexión sobre cómo se articularía el lenguaje escrito con el visual. Hoy, en la producción que recibe más atención crítica priman relaciones complementarias entre texto e imagen o incluso contradictorias (Nikolajeva and Scott 17-18). Llama la atención entonces porque este descalce entre lo visual y lo verbal, no parece responder a una opción estética sino a limitaciones discursivas en relación a cuándo el texto sería apropiado para la infancia. En la ilustración de Ruano vemos simplemente a un hombre que camina solo y un soldado de cabeza gacha lo acompaña más atrás (es relevante que la edición argentina, con ilustraciones de María Delia Lozupone, sí que muestra cómo llevan a rastras al hombre). La narración visual de Ruano — que en algo recuerda el tono y poética de las del autor británico Anthony Browne- evita representar la violencia que el texto evoca en la escena, pero sí parece connotar en otras escenas un ambiente opresivo. Aparecen, por ejemplo, dos páginas con altos muros de ladrillo, infranqueables. Cómo vemos en las Figuras 2 y 3, estos muros han sido escritos por la resistencia y sus palabras han sido $-\mathrm{y}$ probablemente seguirán siendo- borradas por las autoridades. 
CATEDRAL TOMADA: Revista de crítica literaria latinoamericana / Journal of Latin American Literary Criticism Narrando la Dictadura a la Infancia. Imágenes que trafican significados.

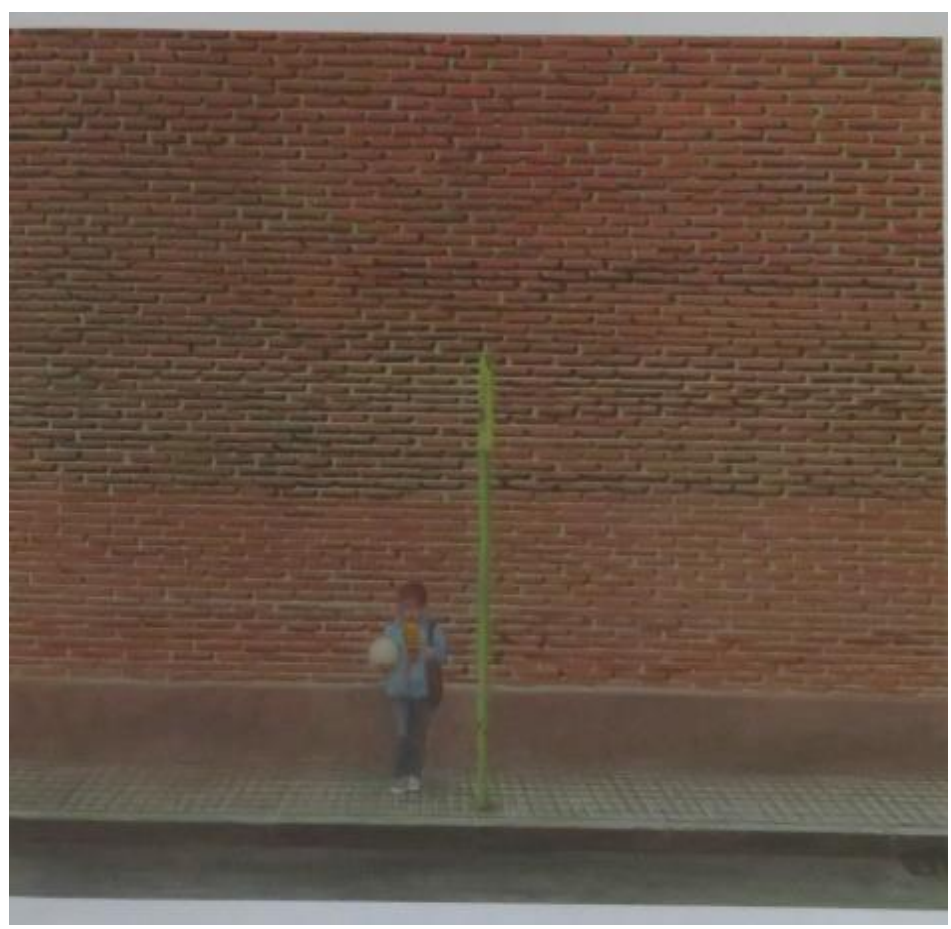

Figura 2. La composición

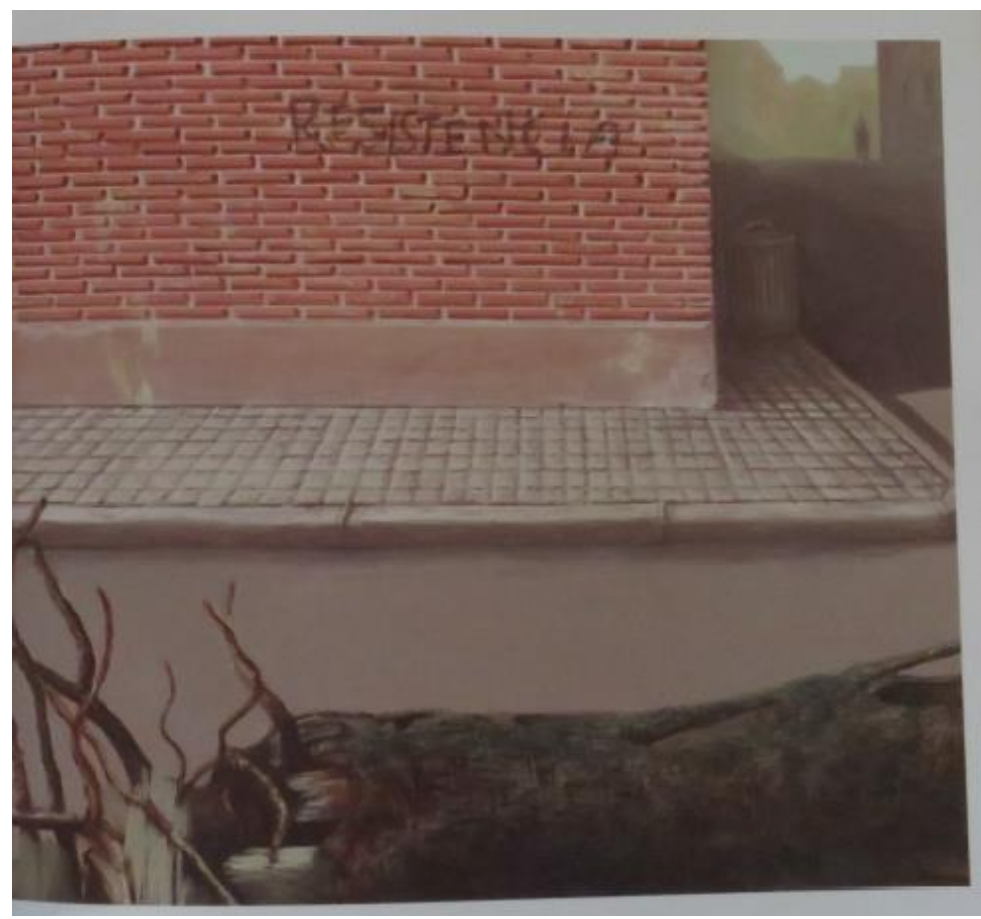

Figura 3. La composición 
En las otras tres obras que revisamos aquí, la relación entre lo visual y lo verbal parece ser algo distinta ya que que es más bien lo visual lo que carga con la responsabilidad de significar las referencias a la violencia de estado y la opresión.

Camino a casa (Jairo Buitrago y Rafael Yockteng, 2008) presenta un caso paradigmático. Este libro, que resultó ganador del concurso Orilla del Viento con el que Fondo de Cultura Económica premia anualmente un libro-álbum, aparece en cuatro de las diez listas de recomendación consideradas en la conformación de nuestro corpus y es un libro que tanto en Chile como en Argentina se usa para referir a las dictaduras militares (Blanc; Hinojosa). El autor colombiano, Jairo Buitrago, sin embargo, establece referencias a la violencia de estado en Colombia, referencias que son sutiles y aparecen solo en la ilustración, bien pudiendo leerse el libro sin ellas. La historia verbal es narrada por una niña que encuentra/imagina a un león que le acompaña en su camino de regreso de la escuela a su casa: “Acompáñame de vuelta a casa. Para tener con quién hablar y no dormirme en el camino./ El largo camino que me aleja de la ciudad. /Vayamos más rápido que todos/ y espérame. Entremos juntos al barrio / y a la tienda donde ya no tenemos crédito. Come con nosotros/y, si quieres, espera que mamá vuelva de la fábrica. Puedes irte de nuevo, si quieres/ pero vuelve cuando te lo pida" (Buitrago and Yockteng sin paginar). 


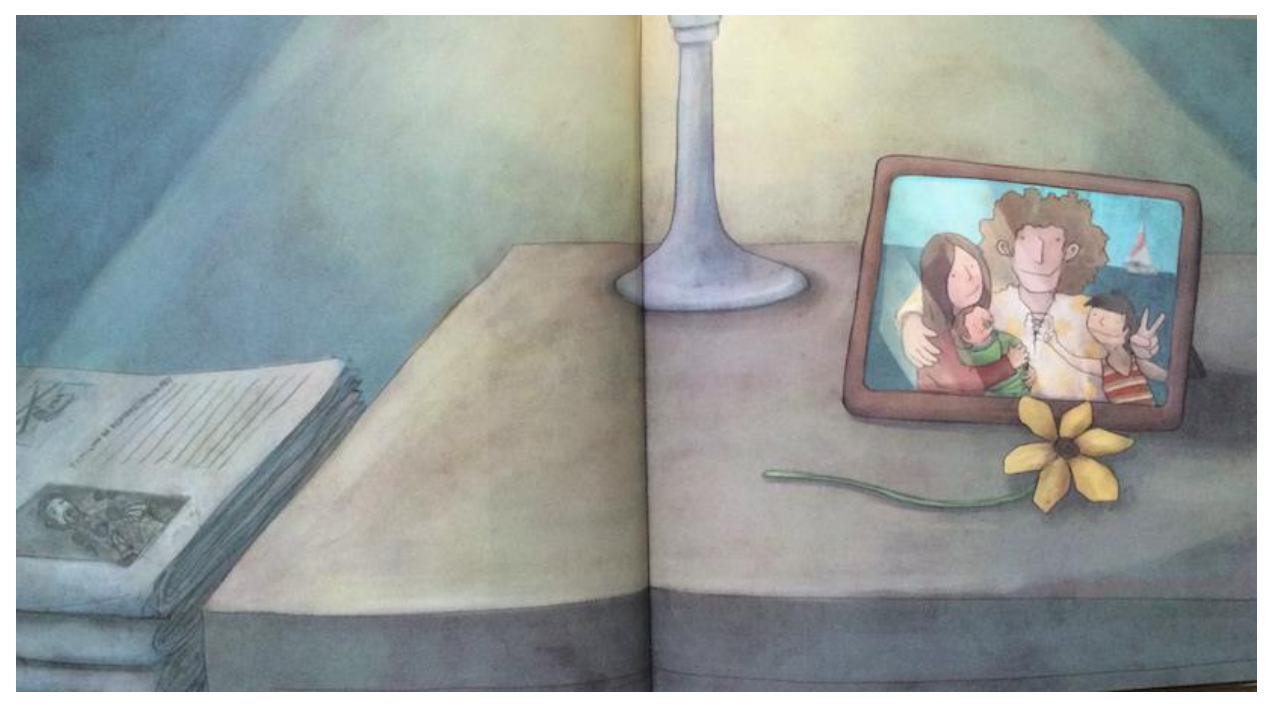

Figura 4. Camino a casa

Durante todo el libro, la niña se dirige a este león que la acompaña. El relato visual es, siguiendo la categorización de Nikolajeva y Scott, contradictorio ya que la narración visual no nos reproduce la perspectiva del texto: el camino no es aburrido, sino hostil. En el almacén no le darían alimentos si no fuese porque el león a su lado ruge. Que hace bien el león en esperarla mientras recoge a su hermano bebé de una guardería porque allí hay también muchos otros niños a la espera que alguien les tome en brazos. Que el león puede irse, pero que la niña que le habla está sola y desamparada aunque haya llegado ya su madre de la fábrica. La madre se ve demacrada y su cabeza gacha confirma esa precariedad y marginación en la que viven. Pero el relato visual nos da además una clave que resignifica todo el relato en una última doble página que no tiene texto verbal. En esta aparece una imagen de familia que incluye a un padre que tiene una melena larga, como de león podríamos decir. Junto a esa foto vemos una ruma de periódicos y el titular "Familias de desaparecidos en 1985" (Figura 4). El lector — ¿adulto? - puede concluir que ese padre es uno de esos desaparecidos, pero, claro está, la historia puede seguirse sin esa referencia: es la imagen la que trafica un significado. 
Un diamante en el fondo de la tierra (Jairo Buitrago y Daniel Blanco, Amanuta, 2015) también le deja la carga de significar a lo visual, aunque en este caso las referencias a la violencia de estado se hacen también en el texto verbal y son necesarias para seguir la historia. En la primeras páginas, las imágenes establecen un mundo narrativo que ya avanza en derribar ciertos tabúes y cambiar una posible perspectiva en el lector. Leemos que "el abuelo de Tania se tomó una foto cuando le dieron una medalla" (Buitrago y Blanco, sin paginar), mientras se nos muestra a un agrio militar, de hombros anchos y anteojos oscuros haciendo un saludo marcial desde una lúgubre habitación (Figura 5).

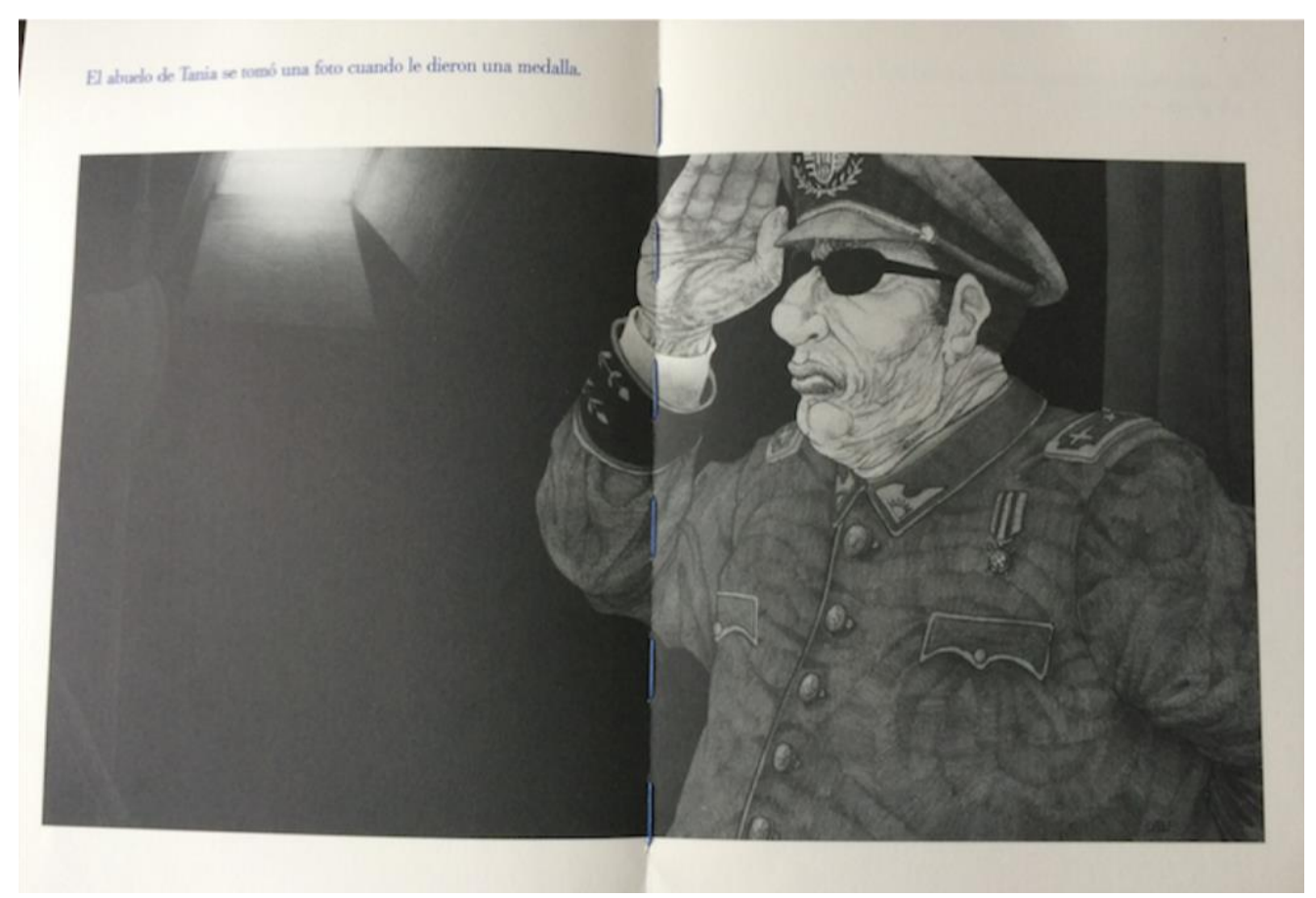

Figura 5. Un diamante en el fondo de la tierra

En la página siguiente, el narrador nos habla de su propio abuelo y el tono es muy distinto. Leemos que "mi abuelo Manuel pintaba murales, se manchaba la ropa, y la abuela se la lavaba" (sin paginar), mientras se muestra al abuelo quitándose una camiseta sobre un andamio. De fondo, un mural de la Brigada 
Ramona Parra —el derecho de esa imagen ha sido cedido para esta edición-, pinceles, botes de pintura, y un folletín "Lucha Popular" (Figura 6).

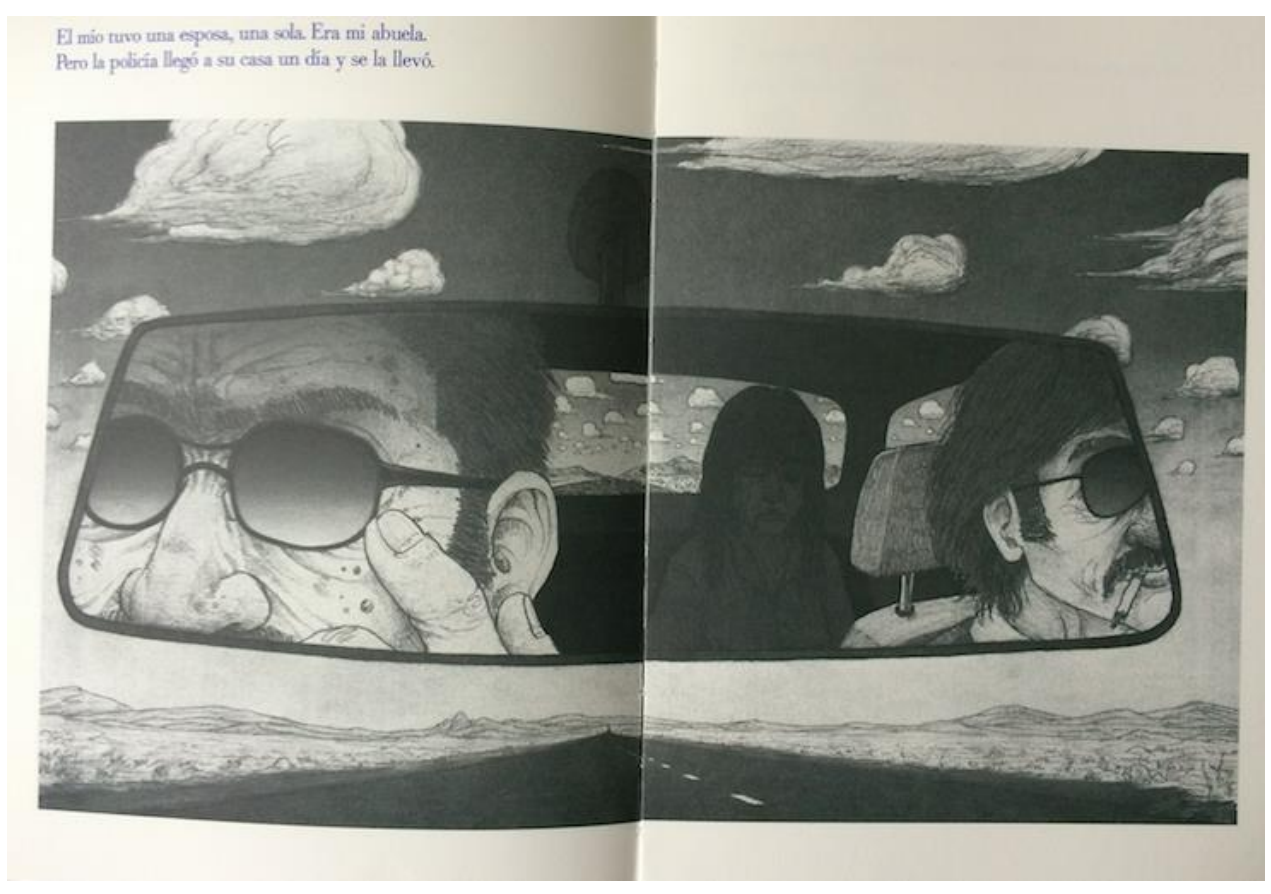

Figura 7. Un diamante en el fondo de la tierra.

La abuela no parece haberse subido al andamio solo para buscar la ropa como sugiere el texto, sino encontrarse pintando a la par que su esposo. Estas páginas preparan un tono emocional para el libro; aquí el relato visual permite poner en cuestión que las condecoraciones sean siempre buenas presentando a la figura de autoridad, el militar, como un personaje del que tomar distancia — niños de siete y ocho años a los que se les leyó esta historia no dudaron en catalogarlo de "malo" rápidamente. Algunas páginas después vemos a la abuela desde el lente retrovisor de un automóvil conducido por hombres de anteojos oscuros. De fondo, un desierto. El texto dice que "la policía llegó a su casa un día y se la llevó" (sin paginar) (Figura 7 ). 


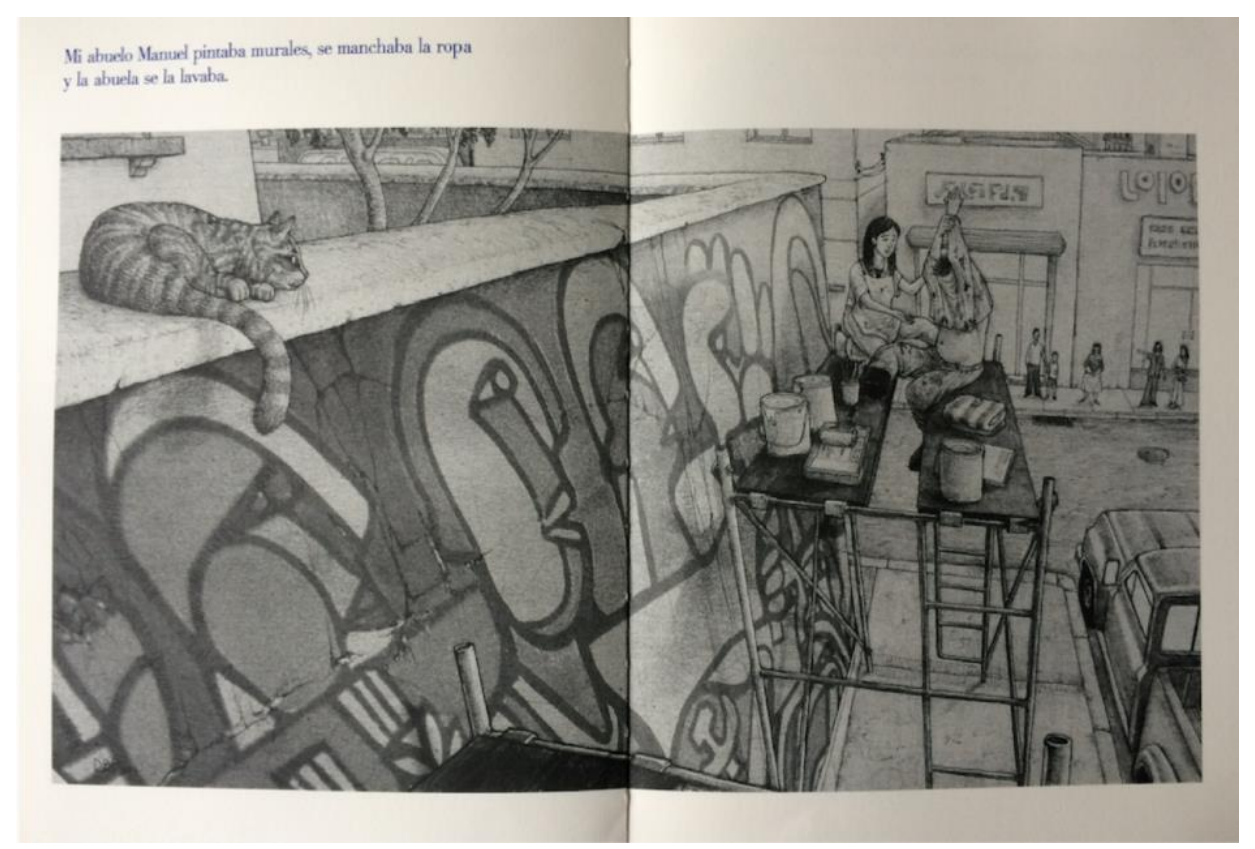

Figura 6. Un diamante el fondo de la tierra

Es la imagen la que nos cuenta adónde, connotando además a uno de los peores episodios de asesinatos masivos durante la dictadura chilena, la Caravana de la Muerte. Esta imagen parece así confirmar que la abuela es una detenida desaparecida, que fue probablemente fusilada y que su cuerpo no fue entregado a sus familiares. Esto, por cierto, está ahí para ser decodificado por un adulto que puede escoger hasta qué punto elaborará esas referencias con el lector de menor edad. Aunque el dibujo a grafito de la abuela con la cabeza gacha y el rostro ensombrecido ciertamente ya alerta sobre su dramática situación a los lectores de todas las edades.

"Bear Story" es un cortometraje sin texto verbal que también trata aunque sólo sea por el marco referencial que le confiere su director-sobre un abuelo exiliado. En este último, las referencias a la violencia de Estado están más desplazadas; ya que no se representa a humanos, sino a animales antropomórficos, en especial a un oso, que vive en una ciudad como las de Latinoamérica. Es quizá 
este desplazamiento del referente lo que posibilita la representación de escenas de mayor violencia física.

"Bear Story" es protagonizada por un solitario oso organillero que ha construido un teatro/caja de música en el que se escenifica la captura de su alterego por un circo. El oso ha sido separado así de su familia y esa historia dentro de la historia acaba con un final feliz en el que se reencuentran. La cinta ha sido presentada por su director, Gabriel Osorio, como haciendo una referencia al exilio de su propio abuelo; quizá de no existir ese marco impuesto por su creador, podría primero leerse como haciendo referencia al maltrato animal. El maltrato de animales circenses está entonces ahí para representar a la tortura en dictadura, una metáfora que suaviza el referente, si estamos de acuerdo en que la tortura de animales recibe menos sanción social (y ciertamente penal) que la de personas. Los militares son evocados a través de los trajes que visten una suerte de robots /domadores que capturan al oso protagonista (Figura 8).

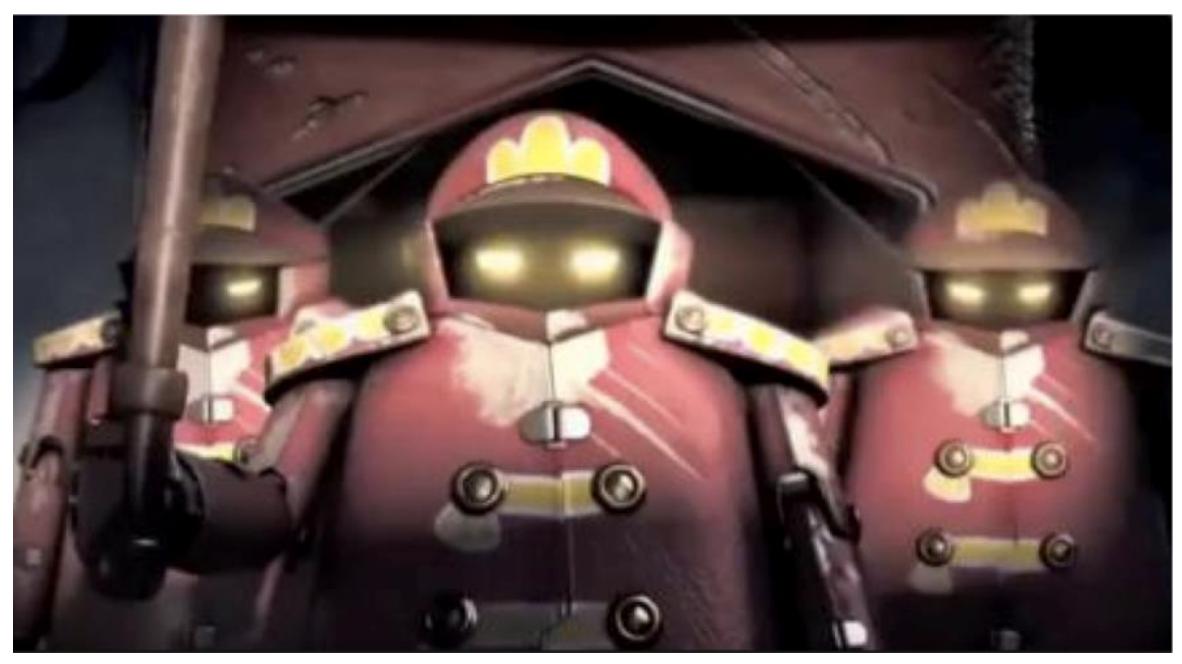

Figura 8. "Bear Story"

La clave en la referencia a militares ejerciendo violencia sobre ciudadanos parece estar en la "luma" (el bastón de madera) que portan, metonimia de la represión en dictadura. 
La trama se estructura así con relatos dentro del relato - lo que Gérard Genette llama historias intradiegéticas - que también operan estableciendo una distancia entre la representación y esa realidad referencial. El oso, que no es un hombre exiliado, sino un oso que vive como hombre, nos cuenta de otro oso al que capturan esos robots domadores. Vemos a esas figuras militarizadas iniciar la persecución, pero el evento mismo de la captura, el momento en que el mazoluma le da en la cabeza al oso alter-ego, el momento en el que se lo separará para siempre de su familia, es mostrado con la proyección de siluetas en ventanas iluminadas de un edificio en medio de la noche, un teatro de sombras (Figura 9).

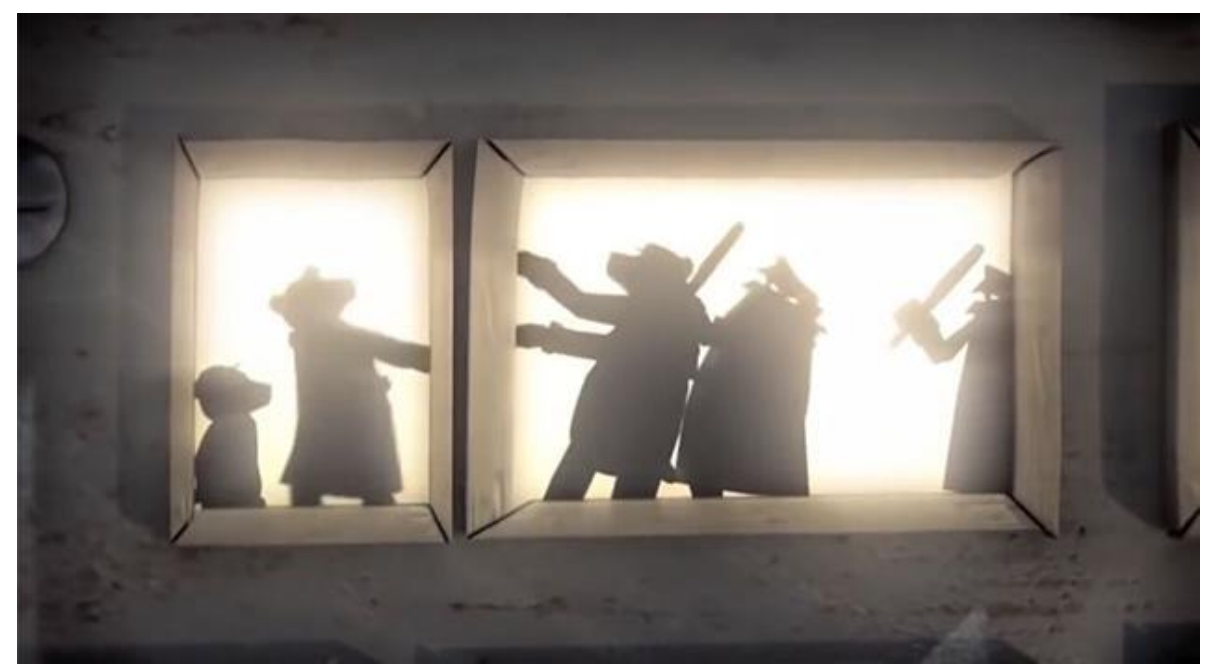

Figura 9. "Bear Story"

Las categorías de modalidad visual ayudan a entender lo que pasa aquí: tenemos una imagen en blanco y negro, sin uso de fondo, de poca luminosidad, y bastante abstracción. Es una imagen de baja modalidad que nos está advirtiendo de su escasa verdad narrativa. Más aún, la escena incluye algunos giros cómicos, por ejemplo, cuando se golpea en la cabeza a una jirafa a la que se ve caer por varias ventanas. La baja modalidad nos advierte que el referente está mediado; que esos domadores no son la policía (secreta) durante la dictadura. 
Tras el éxito de este cortometraje, los realizadores editaron un libro-álbum Historia de un oso (2016) que estuvo durante seis meses en la listas de los más vendidos en Chile. El libro está firmado por Gabriel Osorio, el director del cortometraje, y Antonia Herrera, la directora de arte. En el libro se incluyen textos escritos para describir acciones que la imagen fija no parecía ser capaz de sugerir por sí sola; los textos son bastante descriptivos aunque con focalización en el oso quién, según se nos explica en la primera página, "se sentía solo" (sin paginar). La inclusión del texto escrito da un tono muy distinto al del cortometraje. Siguiendo a Roland Barthes podríamos decir que el texto funciona "anclando" (Barthes 35) uno de muchos posibles significados de la imagen. El libro Historia de un oso reduce así las posibilidades de significación de la imagen, pero también la poética material del cortometraje. Las ilustraciones se han simplificado y coloreado - no hay resabios de la textura del stop motion-, ni música, ni trabajo con el ritmo del libro álbum. Se vuelve a repetir la escena de la captura del oso con un teatro de sombras. Llama la atención que justamente en la doble página donde se retrata esta escena — ahora los distintos animales reciben golpes en la misma imagenno incluya texto escrito. La imagen parece así tener que cargar con la responsabilidad de referir para evitarnos tener que verbalizar. Nombrar esos golpes podría amplificarlos o disminuirlos.

Es la imagen la que trafica significados. Sólo en La composición leemos la palabra "dictadura"; en ninguno de los otros libros se lee exilio, tortura, fusilamiento, detenciones o desapariciones forzadas, sino que se usan expresiones como "marcas en las muñecas", "lo subieron a un camión con otras personas" y "no sabe nada de su país" (en Un diamante en el centro de la tierra, sin paginar). Es bastante sintomático que se incluya en las ilustraciones algunas palabras claves como "resistencia" pintada en un muro en La composición, o "desaparecidos" escrito en la portada de un periódico en la última página de Camino a casa: son palabras que el lector puede decidir si leer o dejar pasar.

El relato a través de polisémicas imágenes pareciese ser entonces más cómodo para el lector adulto y, en especial, para aquel que participa de ese círculo 
mediador del que nos habla Ewers. La reseña de Un diamante en el fondo de la tierra en Canal Lector — sistema de recomendaciones de la Fundación Germán Sánchez Ruipérez en España asociado a las Bibliotecas CRA en Chile y a organización Ibby en México- destaca que: "de las imágenes inferimos que los abuelos del protagonista padecieron una historia terrible durante una dictadura". Llama la atención que esta reseña, elaborada desde las bibliotecas CRA chilenas, indique que se trata de una y no la dictadura, cuando el texto escrito da señas que lo relacionarían con la experiencia chilena, como por ejemplo una página en que se lee: "El abuelo Manuel recogió a mi mamá de la escuela un martes de septiembre. Los aviones de guerra pasaron por encima de ellos" (Buitrago and Blanco sin paginar). Para cualquiera que esté mínimamente familiarizado con el golpe de estado de 1973, la referencia es también clara en lo visual con una vista de edificios del centro de Santiago y el humo de bombas en el cielo. Pero es quizá el hecho de que este libro esté destinado a la infancia lo que hace que quién reseña hable de una dictadura y no la dictadura. Se supone que los niños no tendrán mayor referencia histórica.

Entramos así en un tema que venimos bordeando desde el comienzo de este artículo: ¿cómo se dirigen estos textos a estos dos grupos de lectores, los menores de edad y los adultos mediadores? Un taller de lectura con niños entre cinco y diez años arrojó algunas luces. Leímos con ellos Un diamante en el fondo de la tierra y aún los niños y niñas mayores del grupo, que tenían entre 8 y 10 años, todos lectores entusiastas que participaban por interés propio en un taller semanal en la Biblioteca de Santiago, necesitaron de muchas explicaciones contextuales para seguir la historia. Aún cuando habían escuchado hablar de la dictadura de Augusto Pinochet y del bombardeo al Palacio de la Moneda, hubo que leer la historia dos veces y ayudarles con preguntas (y algunas respuestas). Tanto la primera como la segunda lectura fueron continuamente interrumpidas para preguntar por qué pasaban las cosas y compartir conjeturas de una historia que les parecía extrañísima. Les costaba, por ejemplo, hacer sentido de la detención de la abuela del protagonista. "Tiene que haber sido una criminal", 
aseguró una niña de ocho años. "Quizá se había robado algo”, sospechó un chico de siete. Solo después de intervenir los mediadores, las niñas y niños pudieron considerar la posibilidad de que la abuela fuese inocente y los policías culpables. Es interesante, que la clave para poder integrar esa posibles narrativa fue el detalle de que los policías llevasen lentes de sol: eran villanos, coincidían los jóvenes lectores.

Las cuatro obras aquí analizadas coinciden en estar enmarcadas por sus autores como referentes a la violencia de estado. La circulación de obras para la infancia es especialmente dependiente de aquellos epitextos dirigidos a los adultos que median el consumo. Los cuatro textos analizados aquí circulan con gran aceptación crítica de adultos; podríamos argüir que el lector/espectador implícito (Booth) es entonces ese adulto mediador de quién se espera sepa guiar la lectura del otro lector/espectador implícito, la niña o niño. Cabe aquí la pregunta sobre si esa pulsión por suavizar lo narrado —a través del eufemismo visual y más marcadamente verbal - va más destinada a esos adultos mediadores que evitarían referencias más directas. Más aún, podemos preguntarnos si acaso el rótulo de estas obras como "para la infancia" favorece este juego de signos connotativos y relatos alegóricos y referencias desplazadas. Cabe la pregunta sobre si la aceptación crítica de "Bear Story" dice relación con esta presión que ejerce el marco establecido por sus realizadores que la relaciona con la dictadura y el exilio - más aún, de un hombre identificable, el abuelo del realizador - sobre un texto alegórico que se presenta como dirigido a niños y niñas y habla de un oso y un circo. La celebración del Óscar para este cortometraje fue muy transversal. Fue como si los distintos grupos sociales en pugna por el relato del pasado pudiésen estar de acuerdo en que para los niños y niñas este relato estaba bien.

En julio y octubre de 2016, dirigimos dos talleres de lectura para profesoras y profesores de básica en el que compartimos estos cuatro textos con la intención de explorar mejor los contextos de circulación de éstos. Pese a que enmarcamos estos talleres explícitamente en la relación de estas obras con la dictadura y la memoria —uno de los talleres se realizó en el Museo de la 
Solidaridad Salvador Allende; otro en la Biblioteca de Santiago_-, las respuestas lectoras de los profesores no dieron cuenta de una necesidad o interés de trabajar estos temas. A ellos les parecieron obras interesantes por otras razones. Uno dijo que Camino a casa sería un estupendo libro para sus alumnos porque muchos son hijos de "madre soltera", explicando que "nosotros sabemos que este libro tiene un trasfondo político, pero es tan abierto que pasa a un segundo plano. Los niños se relacionarían desde la emoción”. Otra profesora recalcó la importancia de la estética "vintage" del cortometraje "Historia de un oso" y cómo eso permitiría hablar de la tristeza. Los educadores ahí reunidos parecían interesarse poco en cómo estos libros permitían acercarse a un tema todavía controversial, pero sí en cómo permitirían visibilizar emociones que les parecían "acalladas" en los niños de hoy. Consultados sobre si utilizarían estos textos para hablar de la dictadura en Chile, dijeron que podría ser aunque uno de los presentes indicó que "ése es un tema complicado y no siempre es fácil tratarlo en el aula", una observación apoyada por el resto de los presentes. Solo una profesora que participaba en el segundo de estos talleres hizo ver cómo estos textos permitían hablar de un tema problemático de una forma no tan directa como sería una explicación informativa. Los profesores y profesoras parecieron más inclinados a valorar los dos textos en los que las referencias están más distanciadas: Camino a casa y el cortometraje "Bear Story". Estas respuestas visibilizan la complejidad de abordar la dictadura y violencia de estado en la sala de clase por los difíciles consensos sociales al respecto y, probablemente, en relación a esa idea de que hay que proteger a la infancia de propuestas ideologizadas. El "círculo mediador" del que habla Hans Heino Ewers determinaría así la circulación de una producción textual eufemística.

En los textos vemos cómo los personajes aprenden a vivir en un ambiente opresivo en el que no todo se puede decir y en el que no han de esperar justicia o reparación. A los personajes no se les permite una resistencia frontal, sino salidas de la imaginación y el ingenio: la niña que se crea un león que la proteja en aquel angustioso camino a casa tras la desaparición de su padre; el niño que es obligado 
a reverenciar al militar cuando se presenta en la escuela, pero aún así no sigue sus instrucciones; el oso exiliado que crea una historia en la que escapa de la tortura y se encuentra con su mujer y su hijo. Quizá aún más ilustrativa de la vía de escape que proponen estas obras es la figura del niño que narra Un diamante en el fondo de la tierra: esa narración en primera persona que incluye, sin embargo, distintas voces porque el narrador reproduce las historias de los abuelos de sus compañeros de clase. Intercala así otras historias y otros sufrimientos, al propio, a la historia acallada de sus abuelos. El niño de este cuento ha aprendido a tejer un relato con los retazos de lo que sí le pudieron contar. Este niño, tal como antes Pedro en $L a$ composición, aprendió ya a ajustar lo que cuenta a las formas contables de las que habla la historiadora Molly Andrews, a esos relatos posibles y adecuados a los posibles macrorelatos que estructuran la experiencia en sociedades y momentos determinados (Andrews 36-37). Es la visualidad de Un diamante en el fondo de la tierra la que incluye distintos guiños a cómo las representaciones, lo que contamos, no corresponde del todo a una realidad vivida, no es lo que de verdad se dice, ni tampoco lo que de verdad se entiende. Entre estos guiños tenemos, por ejemplo, un texto que nos cuenta de un abuelo que habría escalado una montaña y habría visto la nieve, cuando la ilustración nos muestra a un hombre posando frente a una montaña rusa de nombre Everest donde se escenifica una cumbre.

Maria Nikolajeva ha observado que "las imágenes visuales pueden ser más eficientes en expresar la vida interna de los personajes, especialmente deseos vagos, no verbalizados, miedos, ensoñaciones y otros estados sicológicos complejos" (Nikolajeva "Picturebook Characterisation: Word/Image Interaction" 46). Una mirada a estas cuatro obras nos muestra así que más que narrar la violencia de estado, lo que se busca es mostrar sus efectos a través de la sugestión y evocación de lo que podríamos llamar un tono emocional de la pérdida. La visualidad de estos textos permitiría acceder a deseos y pesares no verbalizados en el/del contexto en el que circula el libro, abriendo caminos para narrar emociones sin necesidad de verbalizarlas. En ese movimiento, la narración visual emparenta el duelo de las pérdidas por la violencia de estado con otras pérdidas y otras 
violencias — como por ejemplo, la marginalidad económica en Camino a casa, la añoranza de un país de origen en Un diamante en el fondo de la tierra, la "pérdida" de la inocencia en La composición . Estas obras no están modeladas por una estética pedagógica ni comercial. Esto ha de emparentarse por una parte con la propia estética de la producción contemporánea de libro-álbumes, los que Morag Styles y Evelyn Arizpe ven desarrollando una revolución silenciosa en que se cambia del paradigma de lo mimético a lo simbólico (48). Se trata de una producción estética que se aleja del paradigma de géneros más informativos, para elaborar desde lo que podemos suponer es un consenso en que a los niños y niñas se les debiese hablar sobre violencia de estado y de historias de opresión aunque con el cuidado de no entrar demasiado en el tema. Si algo entra es la imagen. La imagen que trafica significados.

\section{Imágenes:}

Figura 1, 2 y 3: La Composición, ilustración de Alfonso Ruano.

Figura 4: Camino a casa, ilustración de Rafael Yockteng.

Figuras 5, 6, 7, 8: Un diamante en el fondo de la tierra. Ilustraciones de Daniel Blanco, texto de Jairo Buitrago.

Figuras 8 y 9: "Bear Story” de estudio Punkrobot.

\section{Bibliografía}

Anabalon, Natalia Alejandra. "Escribir Después Del Desastre: Violencia Y Testimonio En Dos Novelas De Álvaro Bisama." Catedral Tomada. Revista de crítica literaria latinoamericana 4.6 (2016): 90-103. Print.

Andrews, M. Shaping. History: Narratives of Political Change. Cambridge University Press, 2007. Print. 
CATEDRAL Tomada: Revista de crítica literaria latinoamericana / Journal of Latin American Literary Criticism Narrando la Dictadura a la Infancia. Imágenes que trafican significados.

Arizpe, E., and M. Styles. Lectura De Imágenes: Los Niños Interpretan Textos Visuales. Fondo de Cultura Económica, 2004. Print.

Assmann, Jan. "Collective Memory and Cultural Identity." New German Critique.65 (1995): 125-33. Print.

Bal, Mieke. Narratology: Introduction to the Theory of Narrative. University of Toronto Press, 1997. Print.

Barthes, Roland. Lo Obvio Y Lo Obtuso: Imágenes, Gestos, Voces. Paidós, 1986. Print.

Beckett, S. L. Crossover Picturebooks: A Genre for All Ages. Taylor \& Francis, 2013. Print.

Blanc, Natalia. "Literatura Infantil: Cómo Contar La Dictadura a Los Chicos a Través De La Ficción." La Nación 2017. Print.

Booth, W. C. The Rhetoric of Fiction. University of Chicago Press, 2010. Print.

Brown, N. Children's Film: Genre, Nation, and Narrative. Columbia University Press, 2017. Print.

Buitrago, J., and R. Yockteng. Camino a Casa. FCE - Fondo de Cultura Económica, 2015. Print.

Buitrago, Jairo, and Daniel Blanco. Un Diamante En El Fondo De La Tierra. Santiago: Amanuta, 2015. Print.

Evans, J. Challenging and Controversial Picturebooks: Creative and Critical Responses to Visual Texts. Taylor \& Francis, 2015. Print.

Ewers, H.H. Fundamental Concepts of Children's Literature Research: Literary and Sociological Approaches. Routledge, 2011. Print.

González, María José. "Literatura Infantil Chilena Y Dictadura: ¿Un Silencio Elocuente?" Revista digital de libros y literatura infantil y juvenil HUV 17 (2014). Print.

Gubar, Marah. "Innocence." Keywords for Children's Literature. Eds. Nel, P. and L. Paul: New York University Press, 2011. 155-60. Print.

Herrera, Antonia, and Gabriel Osorio. Historia De Un Oso. Zig Zag, 2016. Print. Hinojosa, Hugo. "La Reconstrucción De La Memoria En Un Diamante En El Fondo De La Tierra De Jairo Buitrago Y Daniel Blanco " Umbral. 6 (2016). Web.

Kincaid, James Russell. Erotic Innocence: The Culture of Child Molesting. Duke University Press, 1998. Print.

Kress, G., and Theo Van Leeuwen. Reading Images: The Grammar of Visual Design. Taylor \& Francis, 2006. Print.

Mitchell, William J. T. "What Is an Image?" New Literary History 15.3 (1984): 503-37. Print.

Nikolajeva, M. Children's Literature Comes of Age: Toward a New Aesthetic. Taylor \& Francis, 2015. Print.

. "Picturebook Characterisation: Word/Image Interaction." Art, Narrative and Childhood. Eds. Styles, M. and E. Bearne: Trentham, 2003. 37-49. Print.

Nikolajeva, M., and C. Scott. "How Picturebooks Work." (2001). Print. 
Rose, J. The Case of Peter Pan, or, the Impossibility of Children's Fiction. University of Pennsylvania Press, 1984. Print.

Snell, H., and L. Hutchison. Children and Cultural Memory in Texts of Childhood. Taylor \& Francis, 2013. Print.

Troncoso Araya, Anahí "Un Fatídico Septiembre." Umbral 9.3 (2017): 4-19. Print.

Wall, B. The Narrator's Voice: The Dilemma of Children's Fiction. Macmillan, 1991. Print. 